\title{
"DO TRAVESTISMO ÀS TRAVESTILIDADES": UMA REVISÃO DO DISCURSO ACADÊMICO NO BRASIL ENTRE 2001-2010
}

"DEL TRAVESTISMO HASTA LA TRAVESTILIDAD”: UNA REVISIÓN DEL DISCURSO ACADÉMICO EN BRASIL ENTRE 2001-2010

"FROM TRAVESTISM TO TRAVESTILITIES": A CRITICAL REVIEW OF BRAZILIAN ACADEMIC PRODUCTION (2001-2010)

\author{
Marília dos Santos Amaral, Talita Caetano Silva, Karla de Oliveira Cruz e \\ Maria Juracy Filgueiras Toneli, \\ Universidade Federal de Santa Catarina, Florianópolis/SC, Brasil
}

\begin{abstract}
RESUMO
Observa-se por volta dos anos 2000 uma expressiva visibilidade das experiências travestis e transexuais entre os estudos de gênero e sexualidade, despontando como temáticas centrais de diferentes pesquisas brasileiras. Partindo do expressivo interesse acadêmico pelo universo trans, esta revisão crítica de literatura apresenta o panorama das publicações científicas brasileiras produzidas sobre travestis entre os anos 2001-2010. Trata-se de um mapeamento da literatura especializada, buscada em quatro bases de dados virtuais em língua portuguesa. Por meio de 92 trabalhos selecionados são apresentados os modos pelos quais as experiências travestis têm sido abordadas, trazendo à discussão os movimentos políticos e acadêmicos que envolvem terminologias do "travestismo" às "travestilidades"; a expressiva centralidade de trabalhos em temas como aids, transformação corporal e a prostituição das travestis; o reduzido número de escritos sobre envelhecimento, adolescência, educação entre outros, também relevantes e norteadores de políticas públicas, como por exemplo os levantamentos sobre violências sofridas pelas travestis.
\end{abstract}

Palavras-chave: sexualidade; gênero; travesti; revisão de literatura; Brasil.

\section{RESUMEN}

Se observa en torno a los años 2000, una visibilidad de las experiencias travestis y transexuales entre los estudios de género y sexualidad, sobresaliendo como temáticas centrales de diferentes estudios brasileños. Partiendo del expreso interés académico por el universo trans, esta revisión crítica de la literatura presenta una visión general de las publicaciones científicas brasileñas producidas sobre travestis entre los años 2001-2010. Se trata de un mapa de la literatura especializada en cuatro bases de datos virtuales en portugués. A través de 92 obras, se muestran como las experiencias travestis han sido abordadas, trayendo a la discusión, los movimientos políticos y académicos que envuelven la terminología del "travestismo" hasta "travestilidad"; el centramiento en temas como SIDA, transformación corporal y la prostitución; el reducido número de escritos sobre envejecimiento, adolescencia, educación entre otros, relevantes y guía de las políticas públicas, como por ejemplo las encuestas de violencia que sufren las travestis.

Palabras clave: sexualidad; género; travesti; revisión de literatura; Brasil.

\begin{abstract}
We can observe throughout the years 2000 an increasing visibility of travestilities and transsexual experiences in the gender and sexuality studies, becoming a central thematic in a variety of Brazilian researches. Coming from the expressive academic interest in the trans universe, this critical revision of the literature presents an overview of the Brazilian scientific publication about travestilities between the years $2001-2010$. By mapping the specialized literature, sought on four virtual data in Portuguese, this paper analyzes 92 works. The results demonstrates the different approaches to travesty experiences in terms of the politics and academic movements that involve the terminologies from "travestism" to "travestilities", the expressive number of papers centered on topics related to aids, corporal transformation and travesty prostitution, and a reduced number of works about aging, adolescence, education and others, which are also relevant for guiding public polices, such as the surveys about violence suffered by travesties.
\end{abstract}

Keywords: sexuality; gender; travestilities; review of literature; Brazil. 


\section{Introdução}

Estou atrás do que fica atrás do pensamento. Inútil querer me classificar: eu simplesmente escapulo.

Clarice Lispector

Não faz muito tempo que as experiências travestis e transexuais tornaram-se temáticas para as pesquisas brasileiras ${ }^{1}$. É possível identificar que as categorias "travesti", "travestismo" e "travestilidades" - recorte específico deste artigo - passaram a ser visitadas com mais frequência por pesquisadores das ciências sociais e da antropologia a partir de 1990, sendo detalhadas em diários de campo durante incursões etnográficas por bairros de periferia, boates, praças, pensões e territórios de prostituição de diferentes capitais brasileiras (Benedetti, 2000; Kulick, 1998; Silva, 1993). Neste período, há um crescente e produtivo interesse de pesquisadores pelo tema na seara dos estudos de gênero e sexualidades. É, no entanto, após os anos 2000 que os estudos sobre travestis passam a ter maior visibilidade e despontam como temática central em pesquisas brasileiras. Talvez motivados pela onda dos estudos queer, pelas críticas pósestruturalistas e pela preocupação também crescente entre a militância LGBT (lésbicas, gays, bissexuais, travestis e transexuais) em relação às reivindicações das travestis, os achados demonstram o expressivo interesse acadêmico por suas experiências corporais, políticas e sociais que nesta última década, passaram a fazer parte de pesquisas científicas em variadas áreas do conhecimento.

Baseado nas teses, dissertações, monografias, artigos científicos e resenhas publicadas entre os anos 2001 e 2010, este artigo apresenta os principais temas abordados em relação às travestis e as formas pelas quais categorias em torno de suas experiências foram sendo produzidas pelos discursos científicos no Brasil. Seguindo a linha de pensamento foucaultiana, o presente texto trata de refletir as maneiras pelas quais as travestis tornaram-se objetos de conhecimento, ou seja, as formas como se tornaram alvo de uma grande produção de saberes.

\section{Pistas metodológicas}

O principal enfoque desta revisão crítica de literatura é a produção acadêmica sobre travestis no período entre 2001 e 2010 realizada no Brasil. Para tanto, foram mapeados trabalhos de diferentes categorias acadêmicas: teses, dissertações, monografias, artigos científicos e resenhas. Foram escolhidas as bases de dados virtuais e de livre acesso BVS-Psi, Scielo, Domínio Público e Banco de Teses e Dissertações da Capes, todas em suas versões em português. No campo "pesquisar" de cada uma das bases científicas foram colocados os termos travesti; travestilidade; travestismo e seus plurais, separadamente e combinados com as palavras sexo; gênero; sexualidade; corpo; imagem; corpo e imagem, totalizando 42 tipos de descritores de busca ${ }^{2}$.

Salienta-se que todo o processo de coleta de dados se desenvolveu no período entre setembro de 2010 e abril de 2011, e revisões foram feitas no início de 2012, sendo selecionadas apenas as produções publicadas virtualmente nas bases escolhidas, no período que compreende 2001-2010. Desta forma, novos resultados podem aparecer quando refeitas as buscas nas mesmas bases de dados em diferentes períodos.

Quando se optou por analisar a produção acadêmica sobre travestis como um recorte para este artigo, uma importante discussão emergiu como central: é possível separar trabalhos sobre travestis daqueles produzidos sobre transexuais? Partindo da compreensão de que travestis e transexuais foram temas abordados separadamente até a década de 1990, e que discussões mais amplas no campo dos estudos de gênero e sexualidade têm demonstrado as fragilidades que acompanham a cisão das duas categorias, é possível entender o quanto pode ser uma intransigência tal separação. Sendo assim, a proposta de recorte deste artigo não pretende diferenciar as experiências travestis das transexuais, entendendo que ambas foram categorias produzidas discursivamente, tornando-se temáticas interligadas e transversais, fazendo deslizar as fronteiras que antes as separavam. No entanto, a fim de realizar um mapeamento crítico e que também demonstrasse as aproximações, distanciamentos e tensões que contornam os trabalhos acadêmicos no que tange distinguir/especificar travestis e transexuais, optou-se por não utilizar os termos transexual, transexualismo, transexualidade seus plurais e derivados, na busca pelas bases de dados. Foram considerados os trabalhos que tinham como temas centrais "travestis" e "travestis e transexuais", excluindo os trabalhos que se referiam apenas a transexuais.

\section{Nas pistas do salto alto: buscas, encontros e discussões}

Ao analisar o período das publicações científicas de 2001 a 2010, observa-se que, a partir de 2008, o número de trabalhos produzidos sobre travestis tem 
um grande aumento. Concentram-se em 2009 cerca de $27 \%$ do total de produções da década (25 trabalhos). É também o ano com o maior número de dissertações de mestrado, que se sobressaem como o tipo de trabalho mais desenvolvido sobre travestis $(50 \%)$.

O grande número de trabalhos publicados em 2009 permite acompanhar com mais clareza a gradual mudança das terminologias usadas para conceituar as experiências travestis. É possível traçar um caminho a partir do termo "travestismo" até chegar às "travestilidades" que vem permeando os estudos de gênero e sexualidades desde o início da década. Até o ano de 2004, para referirem-se às travestis, os trabalhos concentravam-se em termos como: travestismo (Cardoso, 2005; P. Garcia, 2004; McClintock, 2003; Patrício, 2002; Tabosa Júnior, 2004), transvestitismo (Azevedo Junior, 2002; Carvalho, 2004) e transgêneros (Jayme, 2001). A partir de 2005, o termo travestilidade, também utilizado no plural, passou a ser frequente entre os pesquisadores (Peres, 2005; Vale, 2005). Sendo entendido por William Peres (2005, p.26) como uma proposta que contempla a "multiplicidade de possibilidades" entre as mais variáveis experiências e modos de vida de travestis, o termo travestilidade tenta não engessá-las em concepções generalistas, levando em consideração suas processualidades e diferentes formas de existência. O conceito ganhou força política, sendo problematizado em 2007, durante o ENTLaids (Encontro Nacional de Travestis e Transexuais). Segundo travestis ativistas entrevistadas por Monica Siqueira (2009), a expressão "travestilidade" também é adotada e vista pelo segmento como uma terminologia que questiona o uso do termo travestismo, assim como o estigma e patologização marcadas pelo sufixo "ismo". Observa-se que os trabalhos produzidos posteriormente a estes debates, entre os anos 2008 e 2009, discutem a terminologia adotada e a importância de seu uso político e conceitual (Cardozo, 2009; Duque, 2009; C. Lima, 2008; Nogueira, 2009; Patrício, 2008; A. Silva, 2008).

Com relação às áreas do conhecimento, os trabalhos encontrados nas bases de dados foram distribuídos em quatro grandes áreas (Humanas e Sociais, Saúde, Comunicação e Educação) identificadas a partir de informações disponibilizadas nas próprias obras, referentes à formação e/ou atuação dos autores -, e respectivas subáreas. Os trabalhos produzidos por autores e coautores de áreas diferentes foram contabilizados em mais de uma categoria, por isso as categorizações não correspondem ao número total de obras analisadas.

Considerando-se as grandes áreas e suas subdivisões, é possível afirmar que os trabalhos concentram-se na área de ciências humanas e sociais. São 59 trabalhos distribuídos principalmente entre as áreas da antropologia (19) e das ciências sociais (16), seguidas pela psicologia (12), a qual, de forma gradativa e especialmente após o ano de 2008, tem demonstrado interesse pelas travestis como temática para suas pesquisas. A antropologia é a área que há mais tempo discute os estudos de gêneros e sexualidades por meio de registros etnográficos e descrições detalhadas acerca dos modos de vida urbanos, o que pode se associar ao destaque no número de produções sobre travestis. À antropologia também estão filiados conhecidos autores no campo do gênero, como Don Kulick, Peter Fry e Richard Parker. Vindos de outros países, estes pesquisadores contribuíram na ampliação dos campos de pesquisa em ciências humanas, agitando as discussões acadêmicas sobre a sexualidade no Brasil. Estes autores que articulam assuntos como experiências travestis, sexualidades e as questões referentes ao HIV/aids, colaboraram na consolidação de um espaço acadêmico para pesquisas sobre travestis na seara dos estudos de gênero e sexualidades.

Na psicologia, a maioria dos trabalhos situa-se em anos mais recentes, 2008 e 2009, são estudos que crescem aliados à psicologia social. A saúde coletiva também tem se debruçado em questões relacionadas às travestis, como nos programas de pós-graduação da Universidade Estadual do Rio de Janeiro (I. Ferreira, 2007; Lacerda, 2006; Peres, 2005) e na Universidade Federal da Bahia (Brignol, 2008; A. Santos, 2007).

Em se tratando da publicação de resenhas, somente quatro foram localizadas nas bases de dados (apenas os periódicos publicam este formato). Um achado interessante é a publicação de uma resenha na área do turismo sobre o livro de Don Kulick (1998), dando ênfase às múltiplas expressões culturais do ativismo LGBT e às movimentações políticas e de direitos em meados da década de 90.

A partir dos títulos das 92 obras localizadas e selecionadas por contemplarem as travestis como temática central sistematizou-se os termos mais utilizados, permitindo identificar que "saúde-doença" e "corpo" são os mais frequentes e correspondem aos principais temas abordados quando o assunto são as travestis.

Tomando como referência o binômio saúdedoença $\left(n=18^{3}\right)$, foram consideradas derivadas deste termo as palavras: saúde, doença, prevenção, aids, HIV, DST, cuidado, risco e vulnerabilidade. A leitura dos resumos permite afirmar que são pesquisas financiadas por agências de saúde, programas de prevenção e/ou redução de danos ligados às drogas 
e doenças sexualmente transmissíveis (DSTs). Tais programas têm se mostrado como um fértil campo para pesquisa, por serem locais de grande circulação de travestis, profissionais do sexo, transexuais e membros de militância LGBT como usuários, agentes de saúde, educadores sociais e/ou participantes de projetos promovidos pelos governos.

Esses são apenas alguns dos motivos que levam a pensar a maneira pela qual o discurso sobre/e das próprias travestis começou a ganhar visibilidade nas políticas públicas e vem se caracterizando desde 2001 até os dias atuais. A atenção a esta população tornouse majoritariamente voltada a ações preventivas e paliativas de saúde, na maioria das vezes percebida pelos profissionais e governos como sinônimo de aids. As demandas governamentais de assistência às travestis continuam diretamente associadas às drogas, à prevenção da criminalidade, ao HIV/aids e às DSTs. Partindo destes enunciados, observa-se que muitos trabalhos têm reproduzido ou problematizado de forma política este contexto. Há um grande número de teses (Carvalho, 2004; Grandi, 2001; Jimenez, 2009; Pelúcio, 2007), dissertações (Borba, 2008; Brignol, 2008; Cassemiro, 2010; Chagas, 2006; Lourenço, 2009; Machay, 2002; A. Santos, 2007), e artigos (Borba, 2010; Lionço, 2008, 2009; Matos et al., 2009; Ministério da Saúde, 2008; Passos \& Figueiredo, 2004; Romano, 2008) escritos sobre a saúde-doença das travestis desde o início da década.

A tese da pesquisadora Larissa Pelúcio (2007), ao problematizar o modelo preventivo da aids entre travestis que se prostituem, analisa alguns efeitos perversos que os programas de prevenção podem apontar ao confinarem as travestis - assim como prostitutas, gays e usuários de drogas - às unidades especializadas em DST/aids, distanciando esta população da prevenção e do cuidado básico com a saúde em geral. Valéria Romano (2008) por meio de relato de experiência discute o trabalho de acolhimento que é realizado com as travestis no Programa Saúde da Família da Lapa/RJ, demonstrando o quanto tal acesso é atravessado por atitudes preconceituosas de profissionais e usuários do SUS. Maria Machay (2002) também se preocupou em analisar a postura dos profissionais de saúde que trabalham nos programas de DST no RJ ao abordar questões referentes ao preconceito e à necessidade de capacitação a estes trabalhadores. A necessidade de informações por parte dos profissionais, também no contexto pernambucano, é apontada por Denise Chagas (2006), que acredita que investimentos nos modelos assistenciais possibilitariam maior aproximação desta população ainda à margem dos espaços de saúde pública.
Sobre prevenção, riscos e sobrevivência das travestis diante do imperativo da aids, o pesquisador João Grandi (2001) investiga a prevalência do HIV nesta população e Rodrigo Borba (2010), em sua pesquisa na região urbana do sul do Brasil, analisa as identidades de gênero e sexualidade construídas em intervenções para distribuição de preservativos. No mesmo caminho, Ailton Santos (2007) analisa o discurso da aids como um estigma entre as travestis profissionais do sexo e, principalmente, as dificuldades de sobrevivência das travestis de camadas populares, nas quais o cuidado com a saúde torna-se algo secundarizado.

O binômio saúde-doença assim como o acesso aos serviços de saúde pública, também são pensados em relação ao processo transexualizador no âmbito do SUS, direito assegurado pela Portaria n. 457, de 19 de agosto de 2008. Em seu artigo, Tatiana Lionço (2009) traz à reflexão o caráter antagônico desta conquista, que, ao mesmo tempo em que denuncia, também restringe os direitos sexuais de travestis e transexuais na área da saúde coletiva, fazendo com que suas identidades permaneçam encapsuladas na patologização de suas vivências.

Um segundo termo muito utilizado pelos pesquisadores brasileiros ao escreverem sobre as travestis é "corpo" $(\mathrm{n}=18)$. Foram consideradas derivadas as palavras: corpo, corporalidade, neca ${ }^{4}$, peitos, transformação, beleza e body building. Nestes trabalhos, os temas gravitam em torno da "reconstrução", do "refazer", das "mudanças" e da "transformação" dos corpos nas experiências travestis. A produção e investimento corporal, também conhecida como "toda feita" (Benedetti, 2000; Tussi, 2005), constantemente é detalhada em etnografias, desde o uso de hormônios até a siliconização líquida ou protética (Goldenberg, 2009). Estes processos corporais ainda ocupam grande espaço entre as pesquisas e são interpretados por alguns autores como inversão de papéis (Cardoso, 2005), formação de identidades (M. Garcia, 2007), expressão de gêneros (Damásio, 2009), informação social (R. Ferreira, 2002), corporalidade (Maluf, 2002) ou subversão das matrizes de gênero (Leite Júnior, 2008; Pelúcio, 2007).

A construção corporal das travestis também é tema de pesquisas não apenas filiadas aos estudos de gênero. O trabalho de Caio Próchno, Maria Nascimento e Maria Romera (2009) a partir do conceito de body building, discute a cirurgia plástica e outros métodos de construção do corpo, entre eles o "travestismo", no intuito de investigar os motivos que levam a busca pelo corpo feminino tanto por homens quanto por mulheres. 
Sobre esta busca da feminilidade, Amanda Lourenço (2009) em sua dissertação no campo da saúde coletiva aborda as possíveis implicações à saúde causadas pela siliconização e hormonização entre travestis. A monografia de Débora Siqueira (2008) apresenta o processo de construção do femininotravesti levando em consideração a diversidade de fatores que atravessam esse processo, como as particularidades da história de vida, o pertencimento a um grupo marginalizado e as transformações corporais e simbólicas vividas pelas travestis.

As modificações corporais na pesquisa de Adrianna Silva (2008) seguem uma abordagem antropológica de gênero e dialogam com as teorias queer. A autora entrelaça o que ela chama de "narrativas da dor", nas experiências travestis, em duas linguagens: uma política, dos discursos sobre as dores do enfrentamento social e da abjeção; e a da satisfação, relacionada às dores de suas transformações corporais, significadas como realização, empreendimento e adequação. Gloria Pereira (2010), também toma o corpo como enfoque, porém segue pistas cartográficas e apresenta por meio de artigos jornalísticos a imagem da travesti na mídia impressa. A tese de Luciene Jimenez (2009) realizada paralelamente entre Diadema/SP e Barcelona, na Espanha, analisa o corpo como território e negociação, e desta forma como referencial laboral e existencial para as travestis que se prostituem.

Outro termo frequente nos títulos das pesquisas sobre travestis é "gênero" $(n=17)$, o que permite uma compreensão próxima aos trabalhos que utilizam o termo "sexualidade" $(\mathrm{n}=06)$. Ambos marcam uma posição teórica e política ao inserirem tais obras no campo dos estudos de gêneros (Borba \& Ostermann, 2008; Firmino, 2009; M. Garcia, 2009; Oliveira, 2006) e sexualidades, assim como em suas variadas vertentes interdisciplinares (Leitão, 2009). O uso do termo também facilita o acesso aos trabalhos por serem facilmente localizados quando são usados, nas buscas em bases virtuais, descritores básicos deste campo teórico.

O termo "identidade" $(n=12)$ também é constantemente usado nos títulos das pesquisas, operando como ferramenta para diferentes discussões, como: construção discursiva das identidades (Borba, 2010; Borba \& Ostermann, 2008), políticas identitárias (Chequer, 2010), produção da identidade no território (Patrício, 2002; P. Santos, 2008), identidade a partir do corpo (Borba, 2008; M. Garcia, 2007; Jimenez \& Adorno, 2009) e até mesmo (ciber)identidades (A. Lima, 2009). No trabalho de Maria Chidiac e Leandro
Oltramari (2004), o termo é utilizado no contexto das "identidades queer", tensionando o jogo de identidades entre o sujeito e a personagem drag queen, diferenciando-as das experiências travestis. Outro debate em que identidade aparece é no sentido de categorias sexuais e políticas, como no artigo de Isadora França (2006), que ao tratar da segmentação do mercado de consumo, aborda a constituição do sujeito político do movimento homossexual num contexto de múltiplas categorias identitárias.

O termo "prostituição" $(n=15)$ também se destaca entre os títulos dos trabalhos, assim como suas variantes consideradas durante a sistematização. São elas: prostituição, pista, trabalhadoras e profissionais do sexo. Durante muito tempo as experiências travestis foram - e em algumas discussões continuam sendo intimamente relacionadas à prática da prostituição. No entanto, tem sido grande o esforço de alguns grupos pela desmistificação das travestis como profissionais apenas do sexo, o que inclui a luta para que tenham direito ao acesso e permanência na escola em todos os níveis, garantindo ainda a profissionalização diversificada. Pensar a centralidade que a prostituição ainda ocupa nos trabalhos acadêmicos envolve a importância de alguns territórios existenciais como espaço de pesquisa de campo ("pista", "rua"). Estes espaços de ampla circulação são também locais de sociabilidade (I. Ferreira, 2007; R. Ferreira, 2003; M. Garcia, 2008; Jeolas, 2009; Ornat, 2008; R. Silva, 2004; Teixeira, 2008; Trigo, 2008). Algumas pesquisas, inclusive, salientam a necessidade de reflexão política que discuta a estigmatização no campo do trabalho e a produção de discursos que invisibilizam e conformam as experiências travestis à marginalização, à prostituição e à vigilância sob o HIV/aids (Chagas, 2006; Jimenez, 2009; Passos \& Figueiredo, 2004; Pelúcio, 2005, 2006, 2007; A. Santos, 2007).

Ainda que trabalhos que se refiram à prostituição de travestis pareçam homogêneos, direções distintas são dadas pelos autores ao tratarem desta questão. Rubens Ferreira (2003), em sua dissertação discute a mobilização política das travestis que se prostituem em Belém, no Pará, e constata as dificuldades da construção da cidadania entre travestis que não estão organizadas na cidade, tal como ocorre em outras capitais brasileiras. Marcio Ornat (2008), pesquisador na área da geografia, analisa o território da prostituição e suas relações de poder. Já Luiz Carlos Jeolas (2009) trabalha em sua dissertação a representação fotográfica de mulheres e travestis profissionais do sexo, e Flávia Teixeira (2008) problematiza o sonho das travestis que querem ir à Europa, mobilizando questões relativas ao tráfico de 
pessoas e as vulnerabilidades às quais travestis estão expostas quando se prostituem fora do Brasil.

Observa-se que algumas discussões ainda são recentes e menos frequentes, mesmo que sejam importantes na produção do discurso especializado sobre travestis. Enfoques diversificados e pouco centrais se sobressaem quando analisados os títulos, resumos e palavras-chave. São eles: o envelhecimento, a adolescência, a violência, educação, parentalidades/ relações conjugais, raça, religião e política.

Pedro Antunes (2010), por exemplo, discute as condições da velhice entre as travestis e o quase inexistente número de pesquisas sobre o tema. Anteriormente, em 2004, Monica Siqueira também trouxe essa discussão em pesquisa etnográfica com travestis com idades entre 59 e 79 anos, analisando o que ela chama de duplo processo de marginalização, "por serem travestis e velhos". Assim como a velhice não é problematizada, jovens travestis também ainda representam um grupo minoritário como alvo de interesses das pesquisas. Uma das poucas publicações acerca do assunto é a dissertação de Tiago Duque (2009), realizada com travestis adolescentes em Campinas/SP. O autor analisa o que denomina novas travestilidades, suas relações com a vergonha e o estigma, as subjetividades produzidas pelos novos dispositivos de controle e as formas de resistência aos códigos hegemônicos.

Outro ponto frágil são as violências sofridas pelas travestis que, embora mencionadas na maioria dos trabalhos, ainda não encontram visibilidade suficiente para que se traduzam em dados que possam, inclusive, subsidiar políticas de enfrentamento. Um dos poucos artigos dedicado ao tema é de Sergio Carrara e Adriana Vianna (2006), que traz dados importantes sobre o perfil social das vítimas e o tratamento policial e jurídico diante destes casos de violência letal contra travestis.

A escolaridade das travestis assim como a relação de professoras travestis com o ambiente escolar são discussões pontuais e urgentes, inclusive para embasar políticas públicas para a educação. Duas dissertações tratam estes temas. Alessandra Bohm (2009) pontua as dificuldades enfrentadas pelas travestis para permanecerem na escola, e Neil Almeida (2009), a partir de entrevistas com professores gays, travestis e lésbicas discute a constituição identitária de professores/as que transitam pelas fronteiras das sexualidades e do gênero.

As parentalidades e as relações conjugais vividas por travestis são temas abordados por Larissa Pelúcio (2006) ao discutir três casamentos de travestis que se prostituem. No mesmo ano, também Elizabeth Zambrano (2006) coloca em xeque as concepções tradicionais sobre família produzidas pela antropologia, psicologia, psicanálise e pelo direito, diante do aumento do número de famílias formadas por pais/mães homossexuais, travestis e transexuais.

Pouco central tambéméa ênfase dadaà intersecção entre raça/etnia, gênero e classe, ainda que pesquisas na área das ciências humanas tenham se mostrado cada vez mais preocupadas com esses marcadores. $\mathrm{O}$ artigo de Laura Moutinho (2006), dedicado à trajetória de vida de três jovens homossexuais negros que vivem no subúrbio carioca, demonstra que há um "campo de manobras" mais amplo entre os jovens homossexuais negros se comparados aos heterossexuais, às lésbicas e às travestis de diferentes cores que habitam a mesma região.

Sobre a religiosidade das travestis apenas dois trabalhos são identificados: o de Luiz Alberto Ribeiro (2009), que mapeia as religiões que aceitam travestis dentro de seus espaços, e o de Patrick Bomfim (2009), que investiga a manifestação religiosa no cotidiano de travestis e transexuais no Distrito Federal. $\mathrm{Na}$ dimensão política, Luanna Mirella (2010) aborda as consequências da colonização da sexualidade e dos movimentos LGBT no Brasil. Jamile Chequer (2010) dá visibilidade em seu trabalho às formas de interação entre Estado, ONG e movimento social, analisando como o Programa Nacional de DST/aids, o movimento social de aids e o movimento social travesti foram se construindo e se redesenhando no processo de interação política. Michelle Agnoleti (2010) discute a conquista de uma cidadania para as travestis, não pela ótica da igualdade, mas sim baseada em seus valores e suas especificidades.

No que diz respeito às palavras-chave, seguindo os mesmos critérios utilizados na análise dos títulos, foram criadas categorias conforme a frequência e pertinência ao tema. Observou-se que as palavras e termos derivados podem auxiliar nas buscas por publicações que falem sobre travestis, assim como o uso de descritores estratégicos. Sobre estes, após o uso de 42 descritores para a busca neste trabalho, salientase que as palavras travesti, travestis, travestismo $e$ travestismos, quando utilizadas em espaços de busca, apresentam o maior número de resultados nas bases virtuais científicas. Em contrapartida, quando utilizados os termos travestilidade e travestilidades, os resultados são quase nulos. Tais dados somados à análise dos títulos, resumos e palavras-chave refletem a frequência com que foram usados os termos com sufixo ismo, como travestismo, transexualismo e homossexualismo, nas obras publicadas nos primeiros 
anos da década, apesar de existir a utilização de tais termos em produções dos anos 2008, 2009 e 2010. Como discutido anteriormente, há uma reivindicação política em torno da despatologização das identidades, a fim de extinguir as relações entre sexualidades não hegemônicas e anormalidade, assim como concepções acerca da cura das sexualidades não orientadas como heterossexuais. Estas problematizações fazem com que a proposta da não-utilização dos ismos seja uma importante estratégia político-conceitual a ser incorporada pelas pesquisas acadêmicas.

No que diz respeito às combinações dos descritores principais - travesti(s), travestismo(s) e travestilidade(s) - com os descritores secundários corpo, gênero, sexo, sexualidade, imagem e corpo, corpo e imagem -, sobressaem-se as combinações com as palavras corpo e gênero.

\section{Reflexões finais}

Este artigo de revisão crítica, ao mapear as publicações acadêmicas brasileiras sobre travestis, entre os anos 2001-2010, teve como intuito localizar e problematizar temas apresentados como centrais, aqueles pouco visibilizados e, principalmente, os movimentos políticos e acadêmicos que envolvem o uso de terminologias que vão desde "travestismo" até "travestilidades". Para isso, percorreu os caminhos que demonstram os modos pelas quais se produziu a categoria travesti e suas multiplicidades no contexto da pesquisa brasileira.

Uma das dificuldades iniciais na sistematização e escrita deste artigo, diz respeito ao seu foco, ou seja, na distinção entre as categorias travesti e transexual, produzida pelo discurso científico, mais precisamente pelo biomédico. O que se percebe na leitura da maioria dos trabalhos publicados é a fragilidade, assim como a ineficiência, quando estas categorias são adotadas como fixas e fundantes. As próprias travestis e transexuais fazem esta denúncia ao borrarem as fronteiras entre estes dois termos, pois estes circundam a multiplicidade de performances de gêneros e sexualidades que nestes casos extrapolam sólidas categorias.

Nestas condições apostou-se em um mapeamento crítico que não definisse um campo específico de estudos sobre travestis deslocado do que se tem produzido sobre transexuais. Ainda que os descritores utilizados pareçam contemplar somente as travestis, não foram excluídos os trabalhos mais abrangentes que trazem travestis e transexuais como temas transversais, e especialmente aqueles que, mesmo sendo sobre travestis, problematizam em suas análises as questões de classe, raça e estigmatização que envolvem a escolha de travestis por se auto-intitularem travestis ou transexuais. Percebeu-se nos trabalhos publicados que as categorias travesti e transexual produzidas no Brasil se esvaziam quando problematizadas em suas especificidades. No entanto salienta-se que este artigo não alcança a pluralidades das expressões de gêneros e sexualidades, não trazendo à discussão as transexualidades masculinas, por exemplo.

Dentro do recorte temporal e temático proposto, o artigo demonstra que a produção do discurso acadêmico sobre travestis ainda está diretamente ligada à prostituição, à vigilância e estigmatização diante do HIV/aids. Porém, também apresenta pesquisas preocupadas com a despatologização das identidades e os empenhos necessários para descriminalizar suas existências. Associações rápidas ainda são feitas entre as experiências travestis, a marginalização, pobreza, drogas, promiscuidade e patologias. Por outro lado, é importante valorizar esforços coletivos que têm ampliado os espaços de questionamento, preocupandose com aspectos como saúde, educação e trabalho. Dentre eles, ressalta-se a criação de ambulatórios de atenção às travestis (existente em São Paulo), a implementação de portarias que permitem o uso de nome social em instituições administrativas, de saúde e educação (projeto de lei em 2010), e as manifestações de apoio do Conselho Federal de Psicologia (2011) pela retirada dos transtornos de identidade de gênero dos manuais internacionais de diagnóstico. São alguns exemplos de movimentos políticos e sociais que também têm se produzido pelo discurso acadêmico e aos poucos se concretizado em políticas públicas de atenção às travestis.

Os estudos mencionados neste artigo apontam para a relevância de mais pesquisas que lancem seu olhar às travestis e suas questões geracionais, acesso e permanência na escola e no trabalho, bem como violências sofridas. Importantes também se fazem pesquisas que apresentem levantamentos e discussões sobre o acesso de travestis à educação, saúde, segurança e assistência social, com o objetivo de embasar políticas de direitos e acesso à cidadania.

\section{Notas}

1 Entendem-se experiências no plural, por se tratar de formas múltiplas de se experienciar as travestilidades, também, seguindo as pistas de Joan Scott (1999), trata-se de problematizar as experiências não como algo que "é" ou "pertence" aos sujeitos, mas as formas pelas quais os sujeitos são produzidos.

2 Em um primeiro momento, 199 trabalhos apareceram como resultados. Uma tabela no programa Microsoft 
Office Excel® foi criada com dez colunas onde cada um dos trabalhos foi especificado em Tipo (teses, dissertação, etc.); Título do trabalho; Ano; Autores; Universidade ou Instituição de origem; Área de conhecimento (dos autores); Bases de dados (onde o trabalho foi encontrado); Palavraschaves; Resumo e Link (endereço virtual de acesso ao conteúdo). Após a exclusão dos trabalhos em que as travestis não eram temas centrais, 92 trabalhos constituíram a base de análise - sendo estes 14 teses, 46 dissertações, 27 artigos, 04 resenhas e 01 monografia -, cinco tabelas diferentes foram criadas a fim de contabilizar: 1) o Ano de expressiva publicação de pesquisas; 2) a Área de conhecimento que tem demonstrado interesse pelo tema; 3 ) as Bases de Dados que mais apresentaram resultados; 4) os termos frequentes nos Títulos; e, por fim, 5) os termos mais citados nas Palavras-chave dos trabalhos produzidos sobre travestis no período buscado. A análise destes itens, aliada a uma revisão crítica dos principais temas abordados nas obras compõem o material discutido neste artigo.

3 Utiliza-se $(\mathrm{n}=)$ para referir-se ao número total de trabalhos encontrados.

4 Gíria de herança africana utilizada entre as travestis para referir-se ao pênis.

\section{Referências}

Agnoleti, M. (2010). Travestis: percursos e percalços para a conquista da cidadania. Dissertação de Mestrado, Programa de Pós-Graduação em Direito, Universidade Federal de Pernambuco, Recife.

Almeida, N. (2009). A diversidade entra na escola: histórias de professores e professoras que transitam pelas fronteiras da sexualidade e do gênero. Dissertação de Mestrado, Programa de Pós-Graduação em Educação, Universidade Federal de Uberlândia, Uberlândia, MG.

Antunes, P. (2010). Travestis envelhecem?. Dissertação de Mestrado, Programa de Estudos Pós-Graduados em Gerontologia, Pontifícia Universidade Católica de São Paulo, São Paulo.

Azevedo Junior, J. (2002). Travesti: o homem borboleta uma compreensão fenomenológica sobre o transvestitismo. Dissertação de Mestrado, Programa de Pós-Graduação em Psicologia, Pontifícia Universidade Católica do Rio Grande do Sul, Porto Alegre.

Benedetti, M. (2000). Toda feita: o corpo e o gênero das travestis. Dissertação de Mestrado, Programa de PósGraduação em Antropologia Social, Universidade Federal do Rio Grande do Sul, Porto Alegre.

Borba, R. (2008). Alteridades em friç̧ão: discurso e identidades na prevenção de DST/aids entre travestis. Dissertação de Mestrado, Programa de Pós-Graduação em Linguística, Universidade Federal do Rio de Janeiro, Rio de Janeiro.

Borba, R. \& Ostermann, A. (2008). Gênero ilimitado: a construção discursiva da identidade travesti através da manipulação do sistema de gênero gramatical. Revista de Estudos Feministas, 16(2), 409-432.

Borba, R. (2010). Intertext(sex)ualidade: a construção discursiva de identidades na prevenção de DST/aids entre travestis. Trab. Ling. Aplic., Campinas, 49(1), 21-37.

Bohm, A. (2009). Os 'Monstros' e a Escola: identidade e escolaridade de sujeitos travestis. Dissertação de Mestrado,
Programa de Pós-Graduação em Educação, Universidade Federal do Rio Grande do Sul, Porto Alegre.

Bomfim, P. (2009). Discriminação e preconceito: identidade, cotidiano e religiosidade de travestis e transexuais. Dissertação de Mestrado, Programa de Pós-Graduação em Psicologia, Universidade Católica de Brasília, Brasília, DF.

Brignol, S. (2008). Estudo epidemiológico das práticas sexuais desprotegidas em uma população de homens e travestis. Dissertação de Mestrado, Programa de Pós-Graduação em Saúde Coletiva, Universidade Federal da Bahia, Salvador.

Cardoso, F. (2005). Inversões do papel de gênero: "drag queens", travestismo e transexualismo. Psicologia Reflexão e Crítica, 18(3), 421-430.

Cardozo, F. (2009). Das dimensões da coragem: socialidades, conflitos e moralidades entre travestis em uma cidade no sul do Brasil. Dissertação de Mestrado, Programa de PósGraduação em Antropologia Social, Universidade Federal de Santa Catarina, Florianópolis.

Carrara, S. \& Vianna, A. (2006). "Tá lá o corpo estendido no chão...": a violência letal contra travestis no município do Rio de Janeiro. Physis, 2(16), 233-249.

Carvalho, R. (2004). Convivendo com a diferença: estratégias de luta simbólica aplicadas no espaço do cuidado de enfermagem mediante a convivência com transgêneros travestis. Tese de Doutorado, Programa de Pós-Graduação em Enfermagem, Universidade Federal do Rio de Janeiro, Rio de Janeiro.

Cassemiro, L. (2010). Tenho direito de ser "Amapô": as trajetórias de travestis e transexuais face a implementação das politicas públicas de Assistência Social e Saúde. Dissertação de Mestrado, Programa de Pós-Graduação em Serviço Social, Pontifícia Universidade Católica do Rio de Janeiro, Rio de Janeiro.

Chagas, D. (2006). Mulheres e travestis trabalhadoras do sexo em Recife: um desafio para a política de prevenção às DST/ $H I V$ e aids. Dissertação de Mestrado, Pós-Graduação em Saúde Coletiva, Centro de Pesquisa AGGEU Magalhães/ FIOCRUZ, Recife, PE.

Chequer, J. (2010). Das ONGs/aids ao movimento social travesti - Interação Estado-sociedade, dinâmicas complexas $e$ identidades em construção. Dissertação de Mestrado, Programa de Pós-Graduação em Ciência Política, Pontifícia Universidade Católica do Rio de Janeiro, Rio de Janeiro.

Chidiac, M. \& Oltramari, L. (2004). Ser e estar drag queen: um estudo sobre a configuração da identidade queer. Estudos de Psicologia (Natal), 9(3), 471-478.

Damásio, A. (2009). Botando corpo (re)fazendo gêneros: uma pesquisa etnográfica sobre travestis e drag queens. Tese de Doutorado, Programa de Pós-Graduação em Ciências Sociais, Universidade Federal do Rio Grande do Norte, Natal.

Duque, T. (2009). Montagens e desmontagens: vergonha, estigma e desejo na construção das travestilidades na adolescência. Dissertação de Mestrado, Programa de PósGraduação em Sociologia, Universidade Federal de São Carlos, São Carlos, SP.

Ferreira, I. (2007). Universo Trans em tempos de inclusão social: qual o lugar da prostituição?. Dissertação de Mestrado, Programa de Pós-Graduação em Saúde Coletiva, Universidade do Estado do Rio de Janeiro, Rio de Janeiro.

Ferreira, R. (2002). A informação social no corpo travesti (Belém, Pará): uma análise sob a perspectiva de Erving Goffman. Ciência da Informação, 38(2), 35-45. 
Ferreira, R. (2003). As bonecas da pista no horizonte da cidadania: uma jornada no cotidiano travesti. Dissertação de Mestrado, Programa de Pós-Graduação em Desenvolvimento Sustentável, Universidade Federal do Pará, Belém.

Firmino, C. (2009). Resenha - Configurações de gênero travesti e configurações de gênero no Brasil. Revista de Antropologia, $52(1), 406-411$.

França, I. (2006). “Cada macaco no seu galho?”: poder, identidade e segmentação de mercado no movimento homossexual. Revista Brasileira de Ciências Sociais, 21(60), 104-115.

Garcia, M. (2007). 'Dragões': gênero, corpo, trabalho e violência na formação da identidade entre travestis de baixa renda. Tese de Doutorado, Programa de Pós-Graduação em Psicologia Social, Universidade de São Paulo, São Paulo.

Garcia, M. (2008). Prostituição e atividades ilícitas entre travestis de baixa renda. Cadernos de Psicologia Social do Trabalho, 11, 241-256.

Garcia, M. (2009). Alguns aspectos da construção do gênero entre travestis de baixa renda. Psicologia USP, 20(4), 597618.

Garcia, P. (2004). Uma leitura de Isobel Gunn, de Audrey Thomas, no contexto do travestismo no discurso feminino. Dissertação de Mestrado, Programa de Pós-Graduação em Letras, Universidade Federal do Rio Grande, Rio Grande, RS.

Goldenberg, M. (2009). Resenha - O gênero das travestis: corpo e sexualidade na cultura brasileira. História, Ciências, Saúde-Manguinhos, 16(4), 1115-1119.

Grandi, J. (2001). Coinfecção HIV, sifilis e hepatites $B$ e $C$ em travestis da cidade de São Paulo, 1992-2000. Tese de Doutorado, Programa de Pós-Graduação em Enfermagem, Universidade Federal de São Paulo, São Paulo.

Jayme, J. (2001). Travestis, transformistas, drag-queens, Transexuais: personagens e máscaras no cotidiano de Belo Horizonte e Lisboa. Tese de Doutorado, Programa de PósGraduação em Ciências Sociais, Universidade Estadual de Campinas, Campinas, SP.

Jimenez, L. (2009). Corpos profanos e transformados: prostituição e prevenção em tempos de aids. Tese de Doutorado, Programa de Pós-Graduação em Saúde Pública, Universidade de São Paulo, São Paulo.

Jimenez, L. \& Adorno, R. (2009). O sexo sem lei, o poder sem rei: sexualidade, gênero e identidade no cotidiano travesti. Cadernos Pagu, 33, 343-367.

Jeolas, L. (2009). Vendo o corpo, vendo a imagem: a auto-representação fotográfica de mulheres e travestis profissionais do sexo do Jardim Itatinga/Campinas. Dissertação de Mestrado, Programa de Pós-Graduação em Artes, Universidade Estadual de Campinas, Campinas, SP.

Kulick, D. (1998). Travesti: Sex, gender and culture among Brazilian transgendered prostitutes. Chicago, IL: The University of Chicago Press.

Lacerda, P. (2006). O drama encenado: assassinatos de gays e travestis na imprensa carioca. Dissertação de Mestrado, Programa de Pós-Graduação em Saúde Coletiva, Universidade do Estado do Rio de Janeiro, Rio de Janeiro.

Leite Júnior, J. (2008). Nossos corpos também mudam: sexo, gênero e a invenção das categorias "travesti" e "transexual" no discurso científico. Tese de Doutorado, Programa de PósGraduação em Ciências Sociais, Pontifícia Universidade Católica de São Paulo, São Paulo.
Leitão, P. (2009). Travestis: um problema de gênero?. Dissertação de Mestrado, Programa de Pós-Graduação em Psicologia, Universidade Católica de Pernambuco, Recife.

Lima, C. (2008). Moda e expressão sexual: redesenho e construção da aparência no grupo das travestis de salvador. Dissertação de Mestrado, Programa de Pós-Graduação em Desenho, Cultura e Interatividade, Universidade Estadual de Feira de Santana, Feira de Santana, BA.

Lima, A. (2009). Quem sou eu: autorrepresentações de travestis no Orkut. Dissertação de Mestrado, Programa de Pós-Graduação em Cultura e Artes, Universidade Federal de Goiás.

Lionço, T. (2008). Que direito à saúde para a população GLBT? Considerando direitos humanos, sexuais e reprodutivos em busca da integralidade e da eqüidade. Saúde e Sociedade, 17(2), 11-21.

Lionço, T. (2009). Atenção integral à saúde e diversidade sexual no Processo Transexualizador do SUS: avanços, impasses, desafios. Physis, 19(1), 43-63.

Lourenço, A. (2009). Travesti: a construção do corpo feminino perfeito e suas implicações para a saúde. Dissertação de Mestrado, Programa de Pós-Graduação em Saúde Coletiva, Universidade de Fortaleza, Fortaleza, CE.

Machay, M. (2002). Estudo da relevância dada à Sexualidade pelos profissionais de saúde na abordagem do paciente atendido nos programas de DST/AIDS no municipio do Rio de Janeiro. Dissertação de Mestrado, Programa de PósGraduação em Sexologia, Universidade Gama Filho, Rio de Janeiro.

Maluf, S. (2002). Corporalidade e desejo: tudo sobre minha mãe e o gênero na margem. Revista Estudos Feministas, 10(1), 143-153.

McClintock, A. (2003). Couro imperial: raça, travestismo e o culto da domesticidade. Cadernos Pagu, 20, 7-85.

Matos, L. et al. (2009). Retenção urinária aguda como complicação tardia de injeção subcutânea de silicone líquido: relato de caso. Einstein, 7(4), 509-511.

Ministério da Saúde. Depto de Apoio à Gestão Participativa. (2008). Saúde da população de gays, lésbicas, bissexuais, travestis e transexuais. Revista de Saúde Pública, 42(3), 570-573.

Mirella, L. (2010). Localidade ou metrópole? Demonstrando a capacidade de atuação política das travestis no mundocomunidade. Dissertação de Mestrado, Programa de PósGraduação em Antropologia, Universidade de Brasília, Brasília, DF.

Moutinho, L. (2006). Negociando com a adversidade: reflexões sobre "raça", (homos)sexualidade e desigualdade social no Rio de Janeiro. Revista Estudos Feministas, 14(1), 103-116.

Nogueira, F. (2009). A saga da beleza: corpo e travestilidade em Fortaleza-CE. Dissertação de Mestrado, Programa de Pós-Graduação em Sociologia, Universidade Federal de Pernambuco, Recife.

Oliveira, L. (2006). Gestões que pesam: performance de gênero e práticas homossexuais em contexto de camadas populares. Dissertação de Mestrado, Programa de Pós-Graduação em Educação, Universidade do Estado do Rio de Janeiro, Rio de Janeiro.

Ornat, M. (2008). Território da prostituição e instituição do ser travesti em Ponta Grossa - Paraná. Dissertação de Mestrado, Programa de Pós-Graduação em Geografia, Universidade Estadual de Ponta Grossa, Ponta Grossa, PR. 
Passos, A. \& Figueiredo, J. (2004). Fatores de risco para doenças sexualmente transmissíveis entre prostitutas e travestis de Ribeirão Preto (SP), Brasil. Revista Panamericana de Salud Pública, 16(2), 95-101.

Patrício, M. (2002). Travestismo: mobilidade e construção de identidades em Campina Grande. Dissertação de Mestrado, Programa de Pós-Graduação em Antropologia, Universidade Federal de Pernambuco, Recife.

Patrício, M. (2008). No truque: transnacionalidade e distinção entre travestis brasileiras. Tese de Doutorado, Programa de Pós-Graduação em Antropologia, Universidade Federal de Pernambuco, Recife.

Pelúcio, L. (2005). Na noite nem todos os gatos são pardos: notas sobre a prostituição travesti. Cadernos Pagu, 25, 217 248.

Pelúcio, L. (2006). Três casamentos e algumas reflexões: notas sobre conjugalidade envolvendo travestis que se prostituem. Revista Estudos Feministas, 14(2), 522-534.

Pelúcio, L. (2007). Nos nervos, na carne, na pele: uma etnografia sobre prostituição travesti e o modelo preventivo de aids. Tese de Doutorado, Programa de Pós-Graduação em Ciências Sociais, Universidade Federal de São Carlos, São Carlos, SP.

Pereira, G. (2010). Cartografias do desejo queer: dispositivos dos corpos travestis. Dissertação de Mestrado, Programa de Pós-Graduação em Psicologia, Universidade Católica de Brasília, Brasília, DF.

Peres, W. (2005). Subjetividade das travestis brasileiras: da vulnerabilidade dos estigmas à construção da cidadania. Tese de Doutorado, Programa de Pós-Graduação em Saúde Coletiva, Universidade do Estado do Rio de Janeiro, Rio de Janeiro.

Portaria n. 457, de 19 de agosto de 2008. (2008). Aprova a Regulamentação do Processo Transexualizador no âmbito do Sistema Único de saúde. Brasília, DF: Ministério da Saúde.

Próchno, C., Nascimento, M., \& Romera, M. (2009). Body building, travestismo e feminilidade. Estudos de Psicologia, Campinas, 26(2), 237-245.

Ribeiro, L. (2009). DEUS é para todos? Travestis, inclusão social e religião. Dissertação de Mestrado, Programa de Pós-Graduação em Serviço Social, Pontifícia Universidade Católica do Rio de Janeiro, Rio de Janeiro.

Romano, V. (2008). As travestis no Programa Saúde da Família da Lapa. Saúde e Sociedade, 17(2), 211-219.

Santos, A. (2007). Percepção do risco de contrair e práticas educativas entre travestis profissionais do sexo. Dissertação de Mestrado, Programa de Pós-Graduação em Saúde Coletiva, Universidade Federal da Bahia, Salvador.

Santos, P. (2008). Entre necas, peitos e picumãs: subjetividade e construção identitária das travestis do Jardim Itatinga. Dissertação de Mestrado, Programa de Pós-Graduação em Educação, Universidade Estadual de Campinas, Campinas, SP.

Scott, J. (1999). "Experiência": tornando-se visível. In A. Silva, M. Lago, \& T. Ramos (Orgs.), Falas de Gênero (A. C. A. Lima, Trad., pp. 21-55). Florianópolis: Editora Mulheres.

Silva, A. (2008). Das narrativas da dor: um estudo sobre práticas de modificações corporais e afetividades na experiência da travestilidade. Dissertação de Mestrado, Programa de Pós-Graduação em Antropologia, Universidade Federal de Pernambuco, Recife.

Silva, H. (1993). Travesti: a invenção do feminino. Rio de Janeiro: Relume-Dumará.
Silva, R. (2004). Mulheres da vida? Um estudo sobre a prostituição feminina. Dissertação de Mestrado, Programa de Pós-Graduação em Sociologia, Universidade Federal de Goiás, Goiânia.

Siqueira, D. (2008). O terceiro sexo? Uma análise sobre o processo de construção do feminino-travesti. Monografia de Graduação, Curso de Psicologia, Universidade Federal de Sergipe, Aracaju.

Siqueira, M. (2004). Sou senhora: um estudo antropológico sobre travestis na velhice. Dissertação de Mestrado, Programa de Pós-Graduação em Antropologia, Universidade Federal de Santa Catarina, Florianópolis.

Siqueira, M. (2009). Arrasando horrores! Uma etnografia das memórias, formas de sociabilidades e itinerários urbanos de travestis das antigas. Tese de Doutorado. Programa de PósGraduação em Antropologia, Universidade Federal de Santa Catarina, Florianópolis.

Tabosa Júnior, F. (2004). Xiré Ade - O olhar de Pierre Fatumbi Verger sobre o travestismo no carnaval. Dissertação de Mestrado, Programa de Pós-Graduação em Comunicação, Universidade Federal de Pernambuco, Recife.

Teixeira, F. (2008). L'Italia dei Divieti: entre o sonho de ser européia e o babado da prostituição. Cadernos Pagu, 31, 275-308.

Trigo, L. (2008). Resenha - Travesti: prostituição, sexo, gênero e cultura no Brasil. Cadernos de Saúde Pública, 24(9), 21952196.

Tussi, F. (2005). Resenha - Toda feita: o corpo e o gênero das travestis. Horizontes Antropológicos, 12(26), 323-327.

Vale, A. (2005). O vôo da beleza: travestilidade e devir minoritário. Tese de Doutorado, Programa de Pós-Graduação em Sociologia, Universidade Federal de Ceará, Fortaleza.

Zambrano, E. (2006). Parentalidades “impensáveis": pais/ mães homossexuais, travestis e transexuais. Horizontes Antropológicos, 12(26), 123-147.

\section{Agradecimentos}

Ao CNPq, pelo apoio à pesquisa que possibilitou este estudo: "Gênero, sexo e corpo: abjeções e devires" contemplada pelo Edital MCT/CNPq/MEC/CAPES n ${ }^{\circ}$ 02/2010, processo $n^{\circ}$ 401478/2010-6.

À equipe do Núcleo de Pesquisa Margens: modos de vida, família e relações de gênero (Departamento de Psicologia/UFSC), pela colaboração e por nos acolher às margens.

Submissão em: 15/11/2012

Revisão em: 23/03/2013

Aceite em: 16/06/2013

Marília dos Santos Amaral é Doutoranda PPGP/UFSC. E-mail: mariliapsico@hotmail.com

Talita Caetano Silva é Graduanda em Psicologia/UFSC, bolsista $\mathrm{IC} / \mathrm{CNPq}$ E-mail: talitacsilva@hotmail.com 
Karla de Oliveira Cruz é Graduanda em Psicologia/UFSC,

bolsista PIBIC/CNPq/UFSC

E-mail: karladeoliveira@hotmail.com

Maria Juracy Filgueiras Toneli é Doutora em Psicologia/ USP, Pós-doutora pela UMinho/PT, professora do

Departamento de Psicologia/UFSC.

Endereço: PPGP-UFSC. Campus Universitário. Trindade.

Florianópolis/SC, Brasil. CEP 88040-900

E-mail: juracy.toneli@gmail.com

\section{Como citar:}

Amaral, M., S., Cruz, K., O., Silva, T. C., Toneli, M. J. F. (2014) "Do travestismo às travestilidades": uma revisão do discurso acadêmico no Brasil entre 2001-2010. Psicologia \& Sociedade, 26(2), 301-311. 